\title{
Оптические свойства многослойных золь-гель пленок оксида цинка
}

\author{
(ㄱ Н.М. Денисов, Е.Б. Чубенко , В.П. Бондаренко, В.Е. Борисенко \\ Белорусский государственный университет информатики и радиоэлектроники, \\ 220013 Минск, Беларусь \\ ฯ E-mail: eugene.chubenko@gmail.com
}

(Получена 4 июля 2017 г. Принята к печати 19 июля 2017 г.)

\begin{abstract}
Исследование структуры, оптических и фотокаталитических свойств многослойных $-1-8$ слоев- пленок оксида цинка, последовательно сформированных золь-гель методом на стеклянных подложках, показало, что после термообработки при $500^{\circ} \mathrm{C}$, независимо от количества слоев, они состоят из произвольно ориентированных гексагональных кристаллических зерен размером 34-40нм, образующих более крупные частицы размером 100-150 нм. С увеличением количества слоев интенсивность экситонной фотолюминесценции уменьшается в 10 раз, увеличивается поглощение света в видимом и ближнем ИК диапазонах, а эффективность фотокаталитического разложения тестового органического красителя родамина В возрастает на $10-12 \%$. Наблюдающиеся изменения связаны с увеличением общей площади межзеренных границ и изменением интегрального количества кислородных вакансий и междоузлий на них по мере увеличения количества слоев, что позволяет управлять свойствами пленочных покрытий из этого полупроводника при их применении в оптоэлектронике, фотовольтаике, фотокатализе.
\end{abstract}

DOI: $10.21883 /$ FTP.2018.06.45918.8677

\section{1. Введение}

Оксид цинка $(\mathrm{ZnO})$ - оксидный прямозонный полупроводник группы $\mathrm{A}^{\mathrm{II}} \mathrm{B}^{\mathrm{VI}} \mathrm{c}$ шириной запрещенной зоны 3.37 эВ (при $300 \mathrm{~K}$ ) и большой энергией связи экситонов (60 мэВ) [1,2], что позволяет ему проявлять эффективную экситонную люминесценцию в ближнем УФ-диапазоне даже при комнатной температуре и пропускать 80-90\% света в видимом диапазоне $[1,3]$. По совокупности физико-химических, электронных и оптических свойств $\mathrm{ZnO}$ считается перспективным для применения в оптоэлектронике, фотовольтаике и в качестве фотокаталитических покрытий $[1,2,4,5]$.

Преимуществом $\mathrm{ZnO}$ по сравнению с другими широкозонными полупроводниками ( $\mathrm{GaN}$ или $\mathrm{AlN})$ является возможность получения наноструктур из этого материала различными методами, такими как осаждение из газовой фазы, химическое и электрохимическое осаждение, золь-гель и гидротермальный синтез $[1,6-8]$. Среди них золь-гель технология выделяется оптимальным сочетанием простоты реализации и небольшими материальными затратами с возможностью многократного повторения процесса формирования наноструктурированных пленок для достижения требуемой толщины всего пленочного покрытия. Однако особенности структуры и свойств таких многослойных покрытий остаются малоизученными, а имеющиеся данные [9-12] противоречивы.

Авторами работ $[9,10]$, получившими многослойные (1-7 слоев) покрытия из $\mathrm{ZnO}$ золь-гель методом отмечено, что при увеличении количества наносимых слоев фотокаталитическая эффективность покрытия возрастает, что они связали с увеличением удельной площади его поверхности. Однако исследование морфологии и структуры таких покрытий показало [11,12], что при росте количества слоев увеличивается размер кристаллитов
$\mathrm{ZnO}$, и было предположено, что покрытие наоборот становится более плотным. При этом также наблюдалось возрастание электропроводности многослойных пленок [12,13]. Поэтому можно предположить, что отмеченное возрастание фотокаталитической эффективности может быть связано не только с изменениями в площади поверхности, но и с изменениями электронных и оптических свойств материала внутри многослойного покрытия.

Цель данной работы - экспериментальное исследование взаимосвязи изменения структуры, оптических свойств и фотокаталитической эффективности многослойных пленок из $\mathrm{ZnO}$, создаваемых золь-гель методом, в зависимости от количества последовательно нанесенных слоев.

\section{2. Методика эксперимента}

Многослойные пленки из $\mathrm{ZnO}$ формировали зольгель методом на стеклянных подложках размером $20 \times 25 \times 1$ мм по ранее отработанной методике [14-16]. Поверхность подложек предварительно очищали в ацетоне и дистиллированной воде. Золь для осаждения $\mathrm{ZnO}$ представлял собой раствор на основе изопропилового спирта $\left(\mathrm{C}_{3} \mathrm{H}_{7} \mathrm{OH}\right)$, моноэтаноламина $\left(\mathrm{NH}_{2}-\mathrm{CH}_{2} \mathrm{CH}_{2}-\mathrm{OH}\right)$ и безводного ацетата цинка $\left(\mathrm{CH}_{3} \mathrm{COO}\right)_{2} \mathrm{Zn}$, находящихся в молярном соотношении 49:7:5. Для формирования $\mathrm{ZnO}$ подготовленные стеклянные подложки погружали в золь на 1 мин, после чего медленно извлекали и сушили при $200^{\circ} \mathrm{C}$ на воздухе. Таким образом наносили от одного до восьми слоев, после чего всю многослойную структуру подвергали отжигу при $500^{\circ} \mathrm{C}$ в течение 30 мин в воздушной атмосфере.

Структуру и фазовый состав сформированных многослойных пленок исследовали методами растровой элект- 

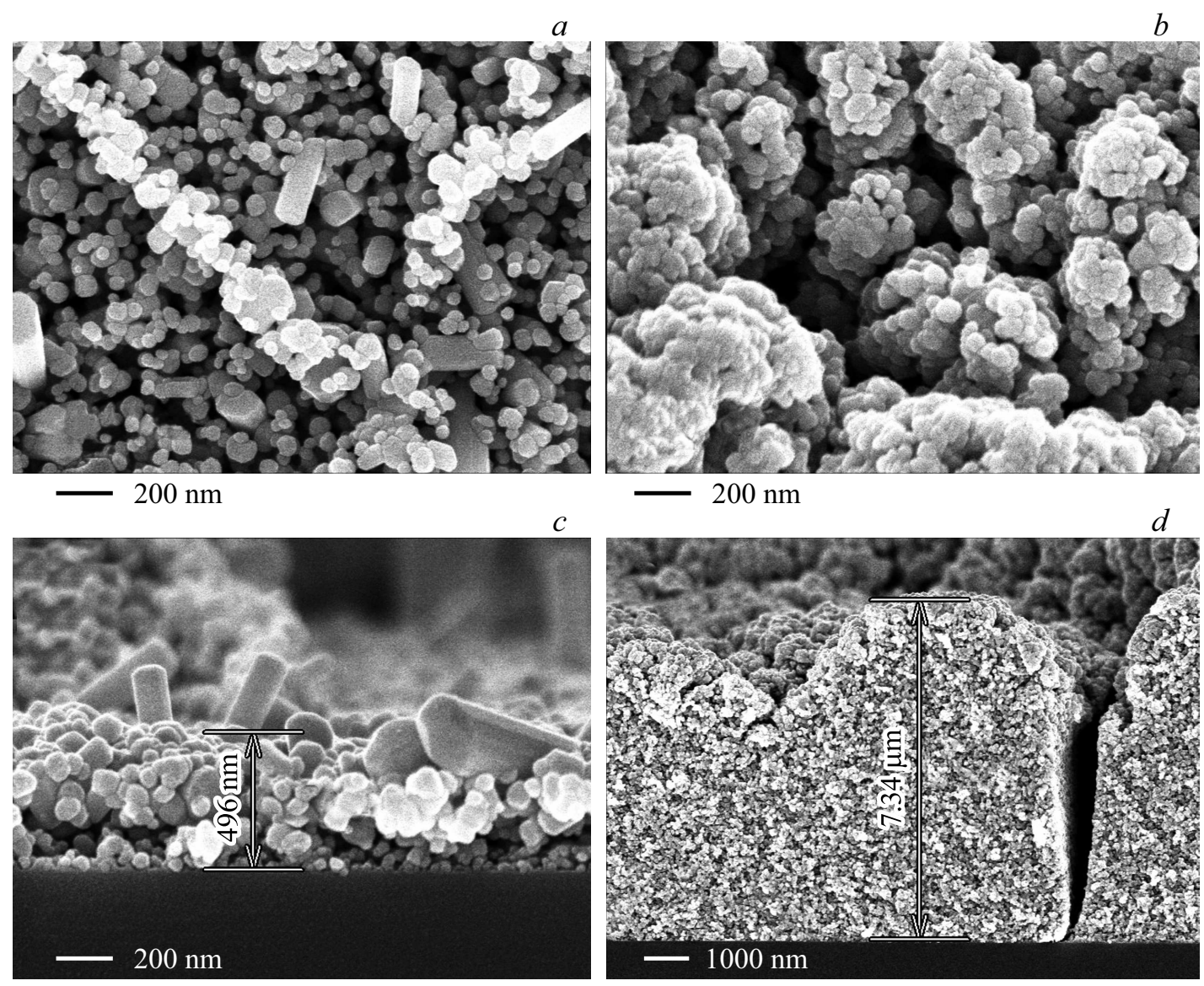

Рис. 1. Поверхность $(a, b)$ и поперечное сечение $(c, d)$ золь-гель пленок $\mathrm{ZnO}$, сформированных на стеклянной подложке и состоящих из $1(a, c)$ и $8(b, d)$ слоев золя.

ронной микроскопии (РЭМ) и рентгеновской дифракторметрии при помощи микроскопа Hitachi S4200 и дифрактометра ДРОН-4 $(\lambda=1.54184 \AA)$ соответственно.

Из оптических характеристик пленок исследовали спектры их отражения и пропускания, а также спектры фотолюминесценции при комнатной температуре. Спектры отражения и пропускания регистрировали с помощью спектрофотометра Proscan MC-121 в диапазоне длин волн 200-1100 нм. Фотолюминесценцию исследовали с использованием спектроскопического комплекса на основе монохроматора-спектрографа Solar TII MS 7504i, оснащенного кремниевой ПЗС-матрицей Hamamatsu S7031-1006S. Возбуждение фотолюминесценции осуществляли ксеноновой лампой мощностью 1 кВт, из спектра излучения которой двойным монохроматором Solar TII DM 160 выделяли монохроматическую линию с длиной волны 345 нм.

Фотокаталитическую эффективность полученных пленок оценивали по разложению тестового органического красителя родамин В (Rh B) в водном растворе под действием ультрафиолетового света. Для этого экспериментальные образцы помещали в чашки Петри с раствором $\mathrm{Rh}$ B c концентрацией 10 мг/л и выдерживали 30 мин в темноте для контроля роли адсорбции красителя в обесцвечивании раствора. Затем раствор с погруженным в него образцом облучали светом от газоразрядной ртутной лампы мощностью 8 Вт в течение 15 мин при постоянном перемешивании раствора. Лампа была снабжена фильтром, выделяющим монохроматическую линию с длиной волны 365 нм. Концентрацию красителя в растворе определяли по величине интенсивности максимума полосы поглощения Rh В на длине волны 556 нм.

\section{3. Результаты}

Все сформированные пленки имеют характерную для поликристаллического $\mathrm{ZnO}$ белую матовую, рассеивающую свет, поверхность. На рис. 1 представлены РЭМ фотографии, иллюстрирующие структуру поверхности и самой пленки в ее поперечном сечении. Независимо от количества нанесенных слоев золь-гель сформированные пленки имеют поверхность с развитым рельефом и состоят преимущественно из сферообразных частиц размером 100-150 нм. При небольшом количестве слоев 1, 2 - на поверхности также имеются стержнеобразные частицы с сечением, близким к шестиграннику с диагональю около 150 нм и длиной до 1 мкм. На поверхности 


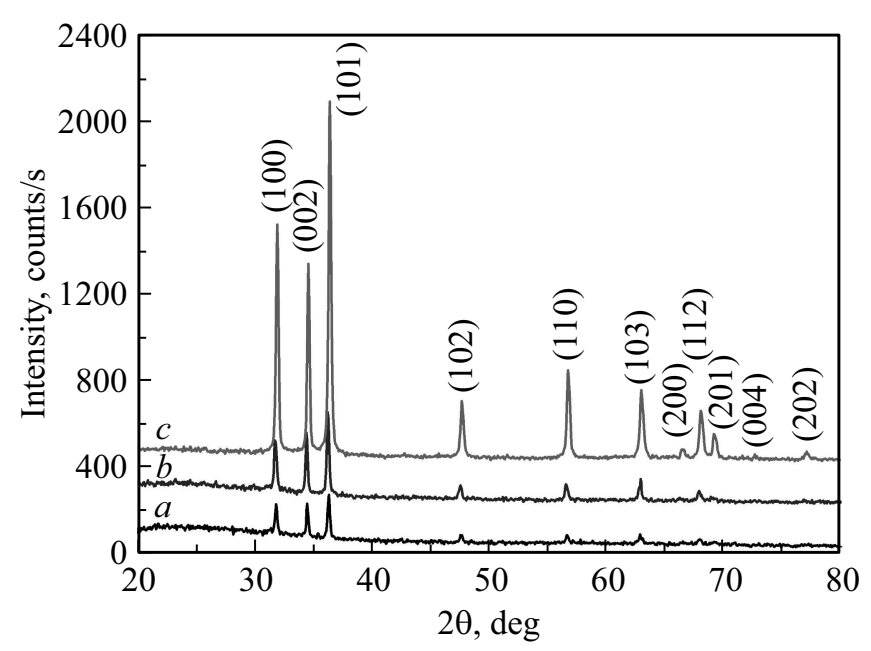

Рис. 2. Рентгеновские дифрактограммы образцов пленок $\mathrm{ZnO}$ с различным количеством слоев: $a-1, b-2, c-8$. На спектрах около каждого дифракционного максимума указаны соответствующие им кристаллические плоскости гексагональной кристаллической решетки $\mathrm{ZnO}$.

8-слойной пленки такие образования отсутствуют, кроме того, отдельные частицы расположены более плотно.

Развитый рельеф поверхности сформированных пленок дает значительный разброс в их толщине. Так, толщина 1-слойных пленок варьируется от 0.5 до 3 мкм, 2-слойных 1-4 мкм, 8-слойных 7-7.4 мкм.

По данным рентгеновской дифрактометрии (рис. 2), все пленки имеют поликристаллическую структуру без выраженной преимущественной ориентации зерен. Полученный набор дифракционных пиков соответствует кристаллическому $\mathrm{ZnO}$ с гексагональной кристаллической решеткой [1]. По мере увеличения количества нанесенных слоев их интенсивность возрастает, что обусловлено большим количеством синтезированного материала. На рентгенодифракционных спектрах для 1- и 2-слойных пленок в области углов $2 \theta=20-30^{\circ}$ наблюдается широкая полоса малой интенсивности, относящаяся к стеклянной подложке.

Рассчитанные по формуле Дебая-Шеррера размеры кристаллитов составляют 34-40 нм для всех зарегистрированных кристаллографических ориентаций $\mathrm{ZnO}$ и не зависят от количества нанесенных слоев. Эти значения меньше размеров частиц, выявленных электронной микроскопией. Рассчитанное для одной кристаллографической ориентации соотношение ширин дифракционных пиков $(\beta)$, соответствующих разным порядкам отражения, имеющим угол отражения $\theta_{1}$ и $\theta_{2}$, соответствует условию $\beta_{1} \beta_{2}=\cos \left(\theta_{2}\right) / \cos \left(\theta_{1}\right)$. Это говорит о том, что наблюдаемое уширение дифракционных пиков обусловлено именно уменьшением размера кристаллитов $\mathrm{ZnO}$. Поэтому целесообразно заключить, что доминирующие частицы размером 100-150 нм, наблюдаемые электронной микроскопией (рис. 1), состоят из кристаллитов размером $34-40 \mathrm{Hм}$.
На рис. 3 представлены спектры пропускания и отражения многослойных пленок $\mathrm{ZnO}$. Пленки пропускают свет в видимом и ближнем ИК-диапазонах с длиной волны более 375 нм, т.е. с энергией фотонов меньше ширины запрещенной зоны этого полупроводника. По мере увеличения количества нанесенных слоев прозрачность пленки уменьшается экспоненциально в соответствии с законом Бугера-Ламберта. Это говорит о том, что средняя толщина пленок увеличивается линейно с ростом количества слоев золя. Отражающая способность пленок также уменьшается с увеличением количества слоев золя, особенно в области длин волн 550-1100 нм.

Поверхность с развитым рельефом приводит к диффузному рассеиванию падающего света, что вызывает фактическое уменьшение измеренных коэффициентов пропускания (рис. 3,a) и отражения (рис. 3,b). Наблюдаемое пропускание пленками света в УФ-диапазоне

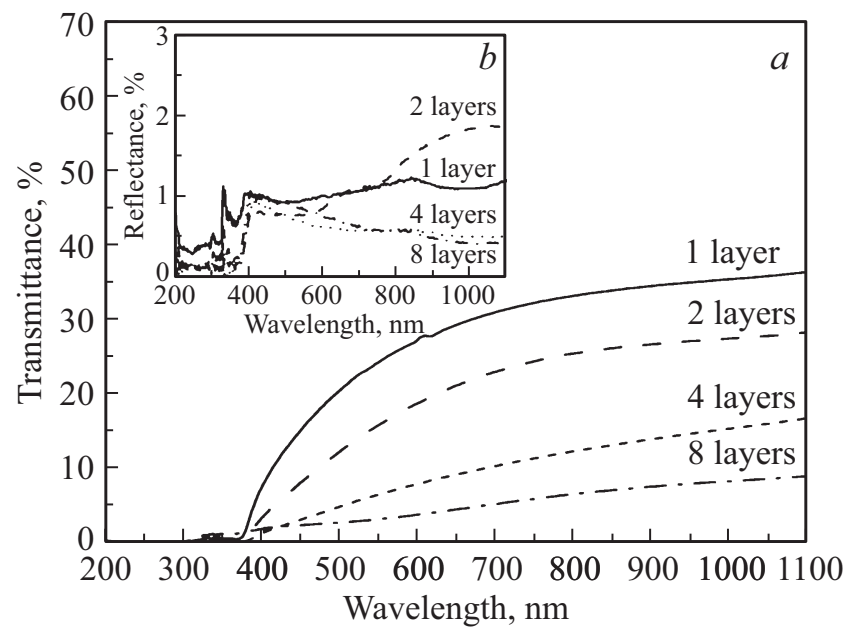

Рис. 3. Спектры пропускания (a) и отражения $(b)$ зольгель сформированных пленок $\mathrm{ZnO}$ с различным количеством последовательно нанесенных слоев.

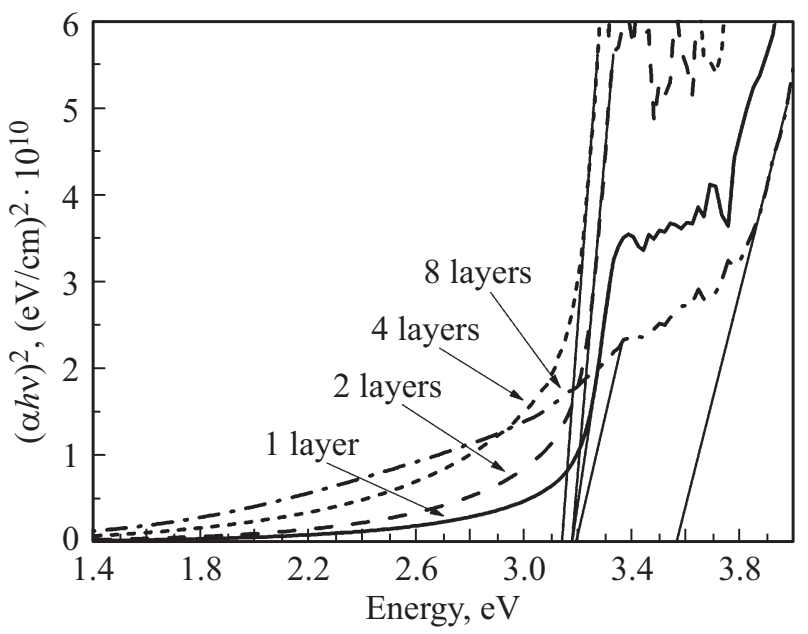

Pис. 4. Спектры поглощения в координатах Тауца для пленок $\mathrm{ZnO}$ с различным количеством слоев. Сплошные прямые линии - экстраполяция краевого поглощения, указывающая на ширину запрещенной зоны. 


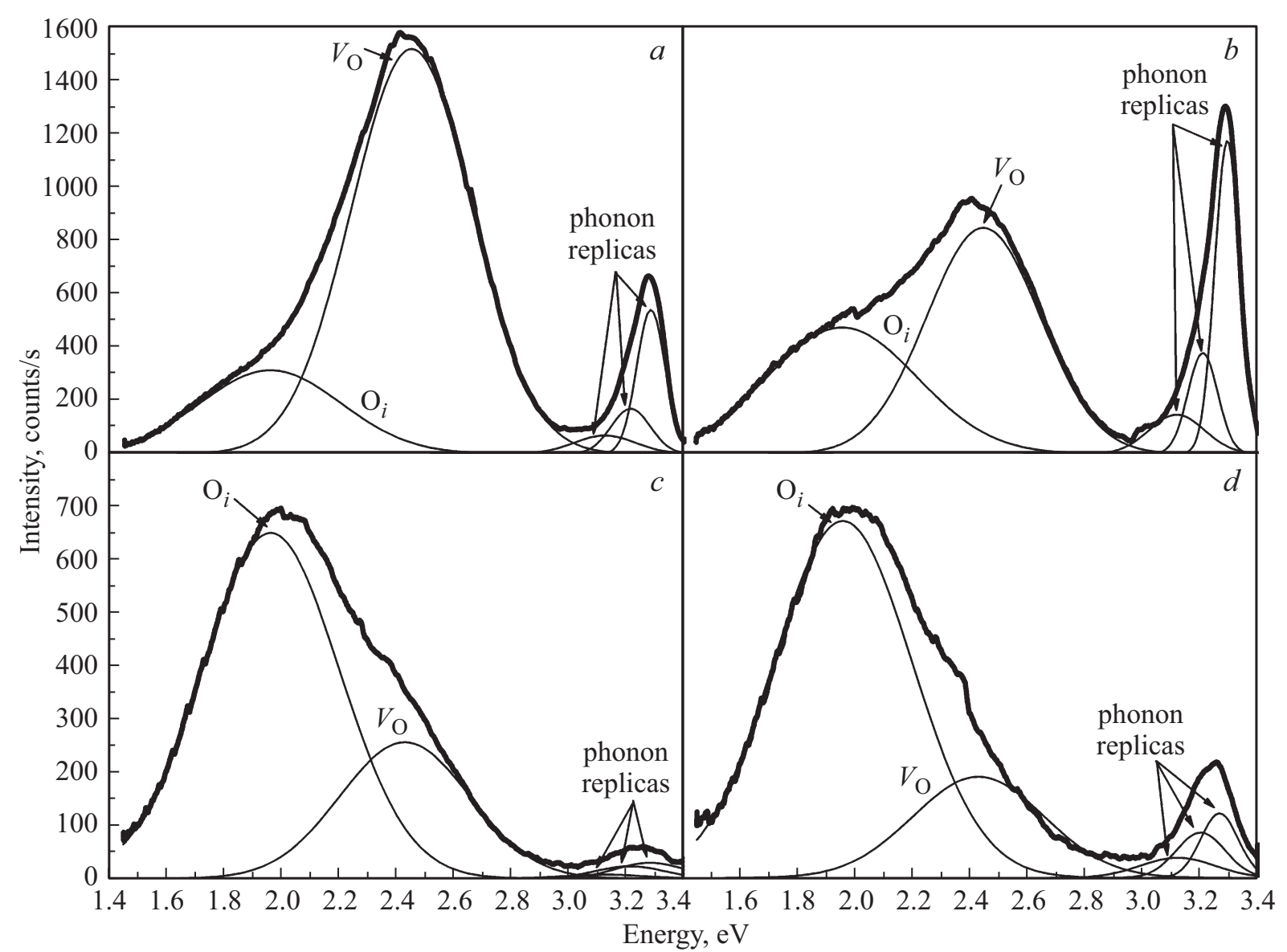

Рис. 5. Спектры фотолюминесценции золь-гель сформированных пленок $\mathrm{ZnO}$ с различным количеством последовательно нанесенных слоев: $a-1, b-2, c-4$ и $d-8$.

300-380нм связано с регистрируемой спектрофотометром фотолюминесценцией $\mathrm{ZnO}$, излучающего свет в более длинноволновом диапазоне при облучении УФ-излучением.

По спектральным зависимостям пропускания и отражения пленок $\mathrm{ZnO}$ были рассчитаны спектры поглощения в координатах Тауца (рис. 4). Определенная по ним оптическая ширина запрещенной зоны $\mathrm{ZnO}$ при различном количестве слоев составила 3.15-3.2 эВ, что меньше значения, соответствующего монокристаллическому $\mathrm{ZnO}(3.34-3.37$ эВ) $[1,2]$.

Спектры фотолюминесценции многослойных пленок $\mathrm{ZnO}$, представленные на рис. 5, демонстрируют существенную зависимость своей формы от количества нанесенных слоев. Следует отметить, что на спектре, соответствующем однослойной структуре, отсутствуют полосы фотолюминесценции, связанные со стеклянной подложкой. Таким образом, даже в случае самой тонкой из полученных образцов пленок глубина проникновения возбуждающего излучения (345 нм) меньше толщины пленки. Следовательно, спектры фотолюминесценции соответствуют излучению приблизительно одинакового объема материала и могут непосредственно сравниваться друг с другом.
В УФ-области спектра люминесценции всех исследуемых образцов наблюдается несимметричная полоса, интенсивность которой убывает с возрастанием количества слоев. Данная полоса состоит из нескольких фононных реплик разного порядка уровня свободных экситонов [17], которые при комнатной температуре за счет температурного уширения сливаются в одну широкую полосу. Максимальную интенсивность имеет компонента, соответствующая 1LO-фононной реплике, максимум которой расположен в области энергии 3.28 эВ. С учетом энергии связи экситонов в $\mathrm{ZnO}$, равной 60 мэВ [1,2], ширину запрещенной зоны $\mathrm{ZnO}$ можно оценить в 3.34 эВ, что соответствует величине запрещенной зоны объемного $\mathrm{ZnO} \quad[1,2]$. Отмеченная выше меньшая ширина запрещенной зоны, определенная по спектрам поглощения, связана с размытием края собственного поглощения из-за присутствия дефектных уровней в запрещенной зоне $\mathrm{ZnO}$ [18].

Полоса фотолюминесценции в оптическом диапазоне спектра имеет большую спектральную ширину (1.4-2.8 эВ). Максимум данной полосы при увеличении количества слоев $\mathrm{ZnO}$ смещается в сторону меньших энергий. При разложении данной полосы на составляющие в форме симметричной гауссовой функции данная 


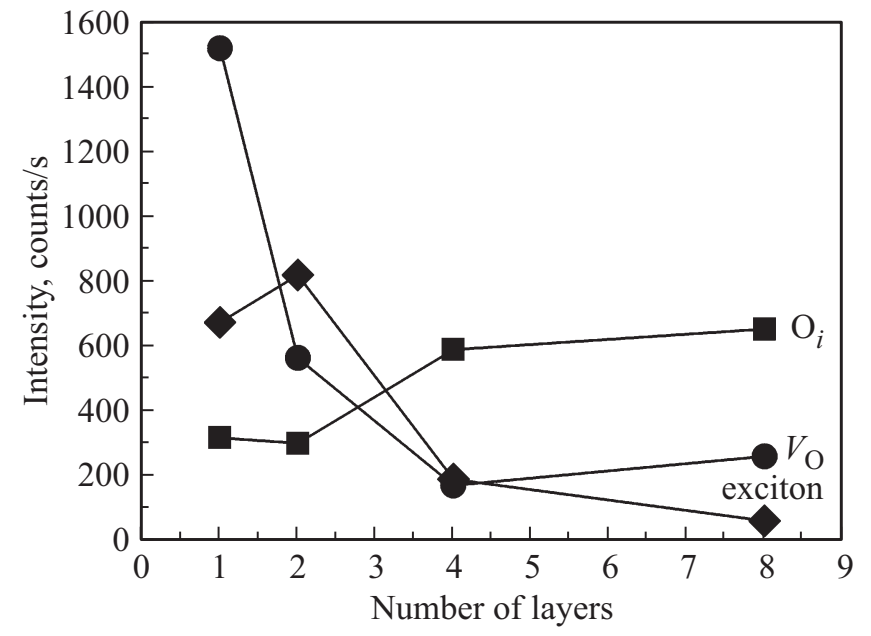

Рис. 6. Изменение интенсивности полос фотолюминесценции, связанных с дефектами кристаллической решетки (междоузельные атомы кислорода $\mathrm{O}_{i}$, кислородные вакансии $V_{\mathrm{O}}$ ), и экситонной фотолюминесценции при увеличении количества слоев $\mathrm{ZnO}$.

полоса для всех образцов хорошо аппроксимируется двумя полосами, максимумы которых соответствуют энергии фотонов 1.96 и 2.45 эВ. Полоса с пиком 1.96 эВ отражает наличие излучательных переходов носителей заряда из зоны проводимости на уровни в запрещенной зоне $\mathrm{ZnO}$, обусловленные присутствием междоузельных атомов кислорода $\left(\mathrm{O}_{i}\right)$ [14], с последующим безызлучательным переходом в валентную зону. Излучательные переходы с энергией около 2.45 эВ связаны с вакансиями кислорода $\left(V_{\mathrm{O}}\right)$ в кристаллической решетке $\mathrm{ZnO}$ [19-22]. Таким образом, у образцов с большим количеством слоев наибольшей интенсивностью обладает полоса, связанная с $\mathrm{O}_{i}$. Полоса экситонной фотолюминесценции в области ближнего УФ и полоса, связанная с вакансионными дефектами $V_{\mathrm{O}}$, при этом затухают (рис. 6).

Исследование фотокаталитической эффективности многослойных золь-гель пленок $\mathrm{ZnO}$ качественно подтвердило отмечавшиеся ранее в $[9,10]$ закономерности. При увеличении количества слоев эффективность фотокаталитического разложения $\mathrm{Rh} \mathrm{B}$ возрастает и для многослойных пленок на $10-12 \%$ больше, чем для однослойной пленки.

\section{4. Обсуждение результатов}

Размытый край собственного поглощения и наличие хорошо заметного хвоста Урбаха на спектрах пропускания (рис. $3, a$ ) указывают на то, что в полученных структурах высока концентрация точечных дефектов. В случае $\mathrm{ZnO}$ в этой роли обычно выступают вакансионные дефекты кристаллической решетки, междоузельные атомы кислорода и цинка, а также атомы посторонних примесей, встроенные в кристаллическую решетку этого полупроводника $[1,23]$. Отмеченное на спектрах отражения уменьшение коэффициента отражения в длинноволновой области оптического диапазона (рис. 3,a), гашение экситонной и дефектной фотолюминесценции (рис. 6) и увеличение хвоста Урбаха у образцов с большим количеством слоев может быть связано с тем, что рельеф и структура поверхности сформированных пленок изменяются в зависимости от количества нанесенных слоев. С увеличением количества слоев интегральное количество дефектов, приводящих к безызлучательной рекомбинации и дополнительному поглощению света, увеличивается.

В процессе фотокатализа эффективность разложения органических веществ связана с количеством центров на поверхности фотокатализатора, через которые происходит передача электронов, участвующих в окислительновосстановительных реакциях в растворе. В качестве таких центров выступают поверхностные дефекты [24]. Поскольку многослойные золь-гель сформированные пленки $\mathrm{ZnO}$ поликристалличны по структуре и имеют поверхность с развитым рельефом, роль дефектов кристаллической решетки у поверхности кристаллитов становится определяющей. По изменению оптических и фотокаталитических свойств она прослеживается при увеличении количества нанесенных слоев от одного до четырех. Большее количество слоев не приводит к их существенному изменению.

\section{5. Заключение}

Многослойные пленки $\mathrm{ZnO}$, формируемые последовательным нанесением слоев золя на стеклянные подложки и термообработкой при $500^{\circ} \mathrm{C}$, независимо от количества нанесенных слоев имеют поликристаллическую структуру, образуемую преимущественно сферообразными частицами размером 100-150 нм, состоящими из гексагональных кристаллитов $\mathrm{ZnO}$ размером 34-40 нм. Основными оптически активными дефектами в них являются междоузельные атомы кислорода и кислородные вакансии в решетке $\mathrm{ZnO}$, локализованные у поверхности кристаллитов. Судя по изменению интенсивности характерных полос фотолюминесценции, по мере увеличения количества нанесенных слоев интегральное количество кислородных междоузлий возрастает, а кислородных вакансий и рекомбинирующих экситонных пар уменьшается. При этом фотокаталитическая эффективность многослойных пленок увеличивается в пределах 10-12\%. Данная закономерность наиболее выражена при изменении количества слоев от одного до четырех, что может быть использовано для управления оптическими и фотокаталитическими свойствами многослойных покрытий из $\mathrm{ZnO}$.

Представленные исследования выполнены в рамках задания 3.2.04 ГПНИ Республики Беларусь „Конвергенция“ и задания 2.1.02 ГПНИ Республики Беларусь „Фотоника, опто- и микроэлектроника““. 
Авторы выражают благодарность Д.В. Жигулину за исследование экспериментальных образцов методом сканирующей электронной микроскопии, а также В.В. Углову за рентгенодифракционный анализ образцов.

\section{Список литературы}

[1] Ü. Özgür, Ya.I. Alivov, C. Liu, A. Teke, M.A. Reshchikov, S. Doğan, V. Avrutin, S.-J. Cho, H. Morkoç. Appl. Phys. Rev., 98, 041301 (2005).

[2] A. Kołodziejczak-Radzimska, T. Jesionowski. Materials, 7, 2833, (2014).

[3] A. Pimentel, E. Fortunato, A. Gonçalves, A. Marques, H. Águas, L. Pereira, I. Ferreira, R. Martins. Thin Sol. Films, 487, 212 (2005).

[4] Ü. Özgür, D. Hofstetter, H. Morkoc. Proc. IEEE, 98, 1255 (2010).

[5] A.B. Djurišić, X. Chen, Y.H. Leung, A.M.C. Ng. J. Mater. Chem., 22, 6526 (2012).

[6] L. Znaidi. Mater. Sci. Eng. B, 174, 18 (2010).

[7] Z. Fan, J.G. Lu. J. Nanosci. Nanotechnol., 5, 1 (2005).

[8] M. Balucani, P. Nenzi, E. Chubenko, A. Klyshko, V. Bondarenko. J. Nanopart. Res., 13, 5985 (2011).

[9] N. Kaneva, A. Bojinova, K. Papazova, D. Dimitrov, I. Svinyarov, M. Bogdanov. Bulg. Chem. Commun., 47, 395 (2015).

[10] А.С. Божинова, Н.В. Канева, И.Е. Кононова, С.С. Налимова, Ш.А. Сюлейман, К.И. Папазова, Д.Ц. Димитров, В.А. Мошников, Е.И. Теруков. ФТП, 47, 1662 (2013).

[11] H.Y. Bae, G.M. Choi. Sensors Actuators B, 55, 47 (1999).

[12] T. Demes, C. Ternon, D. Riassetto, H. Roussel, L. Rapenne, I. Gélard, C. Jimenez, V. Stambouli, M. Langlet. J. Phys. Chem. Solids, 95, 43 (2016).

[13] M.I. Khan, K.A. Bhatti, R. Qindeel, N. Alonizan, H.S. Althobaiti. Results Phys., 7, 651 (2017).

[14] N.M. Denisov, F.A. d'Avitaya, V.E. Borisenko. Inorg. Mater., 50, 572 (2014)

[15] N.M. Denisov, A.V. Baglov, V.E. Borisenko, E.V. Drozdova. Inorg. Mater., 52, 523 (2016).

[16] N.M. Denisov, A.V. Baglov, V.E. Borisenko. Inorg. Mater., 53, 176 (2017).

[17] W. Shan, W. Walukiewicz, J.W. Ager III, K.M. Yu, H.B. Yuan, H.P. Xin, G. Cantwell, J.J. Song. Appl. Phys. Lett., 86, 191911 (2005).

[18] V. Srikant, D.R. Clarke. J. Appl. Phys., 82, 5447 (1998).

[19] S. Vempati, J. Mitra, P. Dawson. Nanoscale Res. Lett., 7, 470 (2012).

[20] B. Cao, W. Cai, H. Zeng. Appl. Phys. Lett., 88, 161101 (2006).

[21] C.H. Ahn, Y.Y. Kim, D.C. Kim, S.C. Mohanta, H.K. Cho. J. Appl. Phys., 105, 013502 (2009).

[22] S. Chakrabarti, D. Ganguli, S. Chaudhuri. Mater. Lett., 58, 3952 (2004).

[23] A. Janotti, C.G. Van de Walle. Rep. Prog. Phys., 72, 126501 (2009).

[24] K.M. Lee, C.W. Lai, K.S. Ngai, J.C. Juan. Water Res., 88, 428 (2016).

Редактор Г.А. Оганесян

\section{Optical properties of multilayered sol-gel $\mathrm{ZnO}$ films}

\author{
N.M. Denisov, E.B. Chubenko, V.P. Bondarenko, \\ V.E. Borisenko
}

\section{Belarusian State University of Informatics and Radioelectronics, 220013 Minsk, Belarus}

\begin{abstract}
Study of structural, optical and photocatalytic properties of multilayered - 1-8 layers - zinc oxide films deposited on glass substrates by sol-gel method showed, that after thermal treatment at $500^{\circ} \mathrm{C}$ they consist of random oriented hexagonal crystalline grains with size of $34-40 \mathrm{~nm}$, forming larger particles with sizes of 100-150 nm, which do not depend on number of layers. With an increase in the number of layers, the intensity of exciton photoluminescence decreases by a factor of 10 , the absorption of light in the visible and near IR ranges increases, and the efficiency of photocatalytic decomposition of the test organic dye rhodamine $\mathrm{B}$ increases by $10-12 \%$. The observed changes are related to the increase in the total area of grain boundaries and to the change in the integral amount of oxygen vacancies and interstitial atoms as the number of layers increases, which makes it possible to control the properties of zinc oxide films for applications in optoelectronics, photovoltaics and photocatalysis.
\end{abstract}

